\title{
Solving a class of functional equations using fixed point theorems
}

\author{
Zeqing Liu' ${ }^{1}$ Haijiang Dong ${ }^{2}$ and Shin Min Kang ${ }^{3 *}$
}

"Correspondence:
smkang@gnu.ac.kr
${ }^{3}$ Department of Mathematics and
RINS, Gyeongsang National
University, Jinju, 660-701, Korea
Full list of author information is
available at the end of the article

available at the end of the article

\begin{abstract}
This paper is concerned with solvability of a class of functional equations arising in dynamic programming of multistage decision processes. Using the fixed point theorems due to Banach and Liu-Ume-Kang and iterative algorithms, some sufficient conditions which ensure the existence, uniqueness and iterative approximations of solutions for the functional equation in the Banach spaces $B C(S)$ and $B(S)$ and the complete metric space $B B(S)$ are provided. Four examples are constructed to illustrate the results presented in this paper.
\end{abstract}

MSC: 49L20; 90C39

Keywords: functional equation; dynamic programming; bounded solutions; continuous bounded solutions; solutions; iterative algorithms; Banach fixed point theorem; Liu-Ume-Kang fixed point theorem

\section{Introduction}

It is well know that the existence problems of solutions for various functional equations arising in dynamic programming are both of theoretical and of practical interest; for example, see [1-19] and the references cited therein. Bellman [2], Bhakta and Choudhury [5], Liu [9] and Liu et al. [11, 12, 14-16, 19] studied the existence, uniqueness and iterative approximations of solutions for the following functional equations arising in dynamic programming:

$$
\begin{aligned}
& f(x)=\inf _{y \in D} \max \{u(x, y), v(x, y) f(a(x, y))\}, \quad \forall x \in S, \\
& f(x)=\inf _{y \in D} \max \{u(x, y), f(a(x, y))\}, \quad \forall x \in S, \\
& f(x)=\sup _{y \in D} \max \{u(x, y), f(a(x, y))\}, \quad \forall x \in S, \\
& f(x)=\operatorname{opt}_{y \in D} \operatorname{opt}\{u(x, y), f(a(x, y))\}, \quad \forall x \in S, \\
& f(x)=\operatorname{opt}_{y \in D}\{u(x, y) \max \{p(x, y), f(a(x, y))\}\}, \quad \forall x \in S, \\
& f(x)=\operatorname{opt}_{y \in D}\{u(x, y) \min \{p(x, y), f(a(x, y))\}\}, \quad \forall x \in S
\end{aligned}
$$

in the complete metric space $B B(S)$, where opt stands for the sup or inf.

\section{祭 Springer}

O2013 Liu et al.; licensee Springer. This is an Open Access article distributed under the terms of the Creative Commons Attribution License (http://creativecommons.org/licenses/by/2.0), which permits unrestricted use, distribution, and reproduction in any medium, provided the original work is properly cited. 
Motivated and inspired by the results in [1-19], in this paper we introduce and study a new functional equation arising in dynamic programming of multistage decision processes as follows:

$$
\begin{aligned}
f(x)= & \lambda \underset{y \in D}{\operatorname{opt}}\{u(x, y) \text { opt }\{p(x, y), f(a(x, y))\}\}+(1-\lambda) \underset{y \in D}{\operatorname{opt}}\{v(x, y) \text { opt }\{q(x, y), f(b(x, y))\} \\
& +t(x, y) \operatorname{opt}\{r(x, y), f(c(x, y))\}\}, \quad \forall x \in S
\end{aligned}
$$

where $\lambda \in[0,1]$ is a constant, $x$ and $y$ stand for the state and decision vectors, respectively, $a, b$ and $c$ denote the transformations of the processes, and $f(x)$ is the optimal return function with initial state $x$. Obviously, functional equation (1.7) includes functional equations (1.1)-(1.6) as special cases. Utilizing the Banach fixed point theorem and Liu-Ume-Kang fixed point theorem, some techniques in nonlinear analysis and a few iterative algorithms, we get the existence, uniqueness and iterative approximations of continuous bounded solutions, bounded solutions and solutions for functional equation (1.7) in the Banach spaces $B C(S)$ and $B(S)$ and the complete metric space $B B(S)$, respectively, and discuss some error estimates between the iterative sequences generated by the iterative algorithms and the solutions. Four nontrivial examples are given to show that the results presented in this paper are more general than those in $[5,6,11,12,14-16,19]$.

\section{Preliminaries}

Throughout this paper, we assume that $(X,\|\cdot\|)$ and $\left(Y,\|\cdot\|^{\prime}\right)$ are real Banach spaces, $S \subset X$ is the state space, $D \subset Y$ is the decision space, $\mathbb{N}$ denotes the set of all positive integers, $\mathbb{N}_{0}=\{0\} \cup \mathbb{N}, \mathbb{R}=(-\infty,+\infty), \mathbb{R}^{+}=[0,+\infty)$ and $\mathbb{R}^{-}=(-\infty, 0]$. Define

$$
\begin{aligned}
& \Phi_{1}=\left\{\varphi: \varphi: \mathbb{R}^{+} \rightarrow \mathbb{R}^{+} \text {is nondecreasing and } \varphi(t)<t\right. \\
& \quad \text { for each } t>0\}, \\
& \Phi_{2}=\left\{(\varphi, \psi): \varphi \in \Phi_{1}, \psi: \mathbb{R}^{+} \rightarrow \mathbb{R}^{+} \text {is nondecreasing and } \sum_{n=0}^{\infty} \psi\left(\varphi^{n}(t)\right)<+\infty\right. \\
& \quad \text { for each } t>0\}, \\
& B(S)=\{g: g: S \rightarrow \mathbb{R} \text { is bounded }\}, \\
& B C(S)=\{g: g \in B(S) \text { is continuous }\}, \\
& B B(S)=\{g: g: S \rightarrow \mathbb{R} \text { is bounded on each bounded subsets of } S\} .
\end{aligned}
$$

Clearly, $\left(B(S),\|\cdot\|_{1}\right)$ and $\left(B C(S),\|\cdot\|_{1}\right)$ are Banach spaces with the norm $\|g\|_{1}=\sup _{x \in S}|g(x)|$. For each $k \in \mathbb{N}$ and $h, g \in B B(S)$, put

$$
\begin{aligned}
& d_{k}(h, g)=\sup \{|h(x)-g(x)|: x \in \bar{B}(0, k)\} \\
& d(h, g)=\sum_{k=1}^{\infty} \frac{1}{2^{k}} \cdot \frac{d_{k}(h, g)}{1+d_{k}(h, g)}
\end{aligned}
$$


where

$$
\bar{B}(0, k)=\{x: x \in S \text { and }\|x\| \leq k\} .
$$

Obviously, $\left\{d_{k}\right\}_{k \in \mathbb{N}}$ is a countable family of pseudometrics in $B B(S)$. A sequence $\left\{x_{k}\right\}_{k \in \mathbb{N}}$ in $B B(S)$ is said to converge to a point $x \in B B(S)$ if $d_{k}\left(x_{n}, x\right) \rightarrow 0$ as $n \rightarrow \infty$ and $\left\{x_{n}\right\}_{n \in \mathbb{N}}$ is a Cauchy sequence if $d_{k}\left(x_{n}, x_{m}\right) \rightarrow 0$ as $n, m \rightarrow \infty$ for each $k \in \mathbb{N}$. It is clear that $(B B(S), d)$ is a complete metric space.

Lemma 2.1 ([12]) Let $E$ be a set, $p$ and $q: E \rightarrow \mathbb{R}$ be mappings. If opt $_{y \in E} p(y)$ and opt $_{y \in E} q(y)$ are bounded, then

$$
|\underset{y \in E}{\operatorname{opt}} p(y)-\underset{y \in E}{\operatorname{opt}} q(y)| \leq \sup _{y \in E}|p(y)-q(y)| .
$$

Lemma $2.2([14])$ Let $\alpha, \beta, \gamma$ and $\delta$ be in $\mathbb{R}$. Then

$$
|\operatorname{opt}\{\alpha, \beta\}-\operatorname{opt}\{\gamma, \delta\}| \leq \max \{|\alpha-\gamma|,|\beta-\delta|\} .
$$

Lemma 2.3 (Liu-Ume-Kang fixed point theorem [17]) Let $(G, \rho)$ be a complete metric space, $\left\{\rho_{k}\right\}_{k \in \mathbb{N}}$ be a countable family of pseudometrics on $G$ such that for any different points $x, y \in G, \rho_{k}(x, y)>0$ for some $k \in \mathbb{N}$, and $\rho$ be defined by

$$
\rho(x, y)=\sum_{k=1}^{\infty} \frac{1}{2^{k}} \cdot \frac{\rho_{k}(x, y)}{1+\rho_{k}(x, y)}, \quad \forall x, y \in G
$$

Assume that $T: G \rightarrow G$ satisfies that

$$
\rho_{k}(T x, T y) \leq \varphi\left(\rho_{k}(x, y)\right), \quad \forall(x, y, k) \in G^{2} \times \mathbb{N}
$$

where $\varphi: \mathbb{R}^{+} \rightarrow \mathbb{R}^{+}$is upper semicontinuous from the right on $\mathbb{R}^{+}$and $\varphi(t)<t$ for each $t>0$. Then $T$ has a unique fixed point $w \in G$ and $\lim _{n \rightarrow \infty} T^{n}(x)=w$ for each $x \in G$.

\section{Main results}

Now we investigate the existence, uniqueness and iterative approximations of continuous bounded solutions and bounded solutions for functional equation (1.7) in the Banach spaces $B C(S)$ and $B(S)$, respectively, by using the Banach fixed point theorem and iterative algorithms.

Theorem 3.1 Let $S$ be compact, $\lambda \in[0,1]$ and $\alpha \in[0,1)$. Let $p, q, r, u, v, t: S \times D \rightarrow \mathbb{R}$ and $a, b, c: S \times D \rightarrow S$ satisfy that

(C1) $p$, $q$ and $r$ are bounded in $S \times D$;

(C2) $\sup _{(x, y) \in S \times D} \max \{|u(x, y)|,|v(x, y)|+|t(x, y)|\} \leq \alpha$;

(C3) for each $\left(x_{0}, g\right) \in S \times\{p, q, r, u, v, t, a, b, c\}$,

$$
\lim _{x \rightarrow x_{0}} g(x, y)=g\left(x_{0}, y\right) \quad \text { uniformly for } y \in D \text {. }
$$

Then functional equation (1.7) possesses a unique solution $w \in B C(S)$ such that 
(C4) for each $w_{0} \in B C(S)$, the iterative sequence $\left\{w_{n}\right\}_{n \in \mathbb{N}_{0}}$ defined by

$$
\begin{aligned}
w_{n}(x)= & \lambda \underset{y \in D}{\operatorname{opt}}\left\{u(x, y) \operatorname{opt}\left\{p(x, y), w_{n-1}(a(x, y))\right\}\right\} \\
& +(1-\lambda) \operatorname{opt}_{y \in D}\left\{v(x, y) \operatorname{opt}\left\{q(x, y), w_{n-1}(b(x, y))\right\}\right. \\
& \left.+t(x, y) \operatorname{opt}\left\{r(x, y), w_{n-1}(c(x, y))\right\}\right\}, \quad \forall(x, n) \in S \times \mathbb{N}
\end{aligned}
$$

converges to $w$ and has the error estimate:

$$
\begin{aligned}
& \left\|w_{n}-w\right\|_{1} \leq \alpha^{n}\left\|w_{0}-w\right\|_{1} \quad \text { and } \\
& \left\|w_{n}-w\right\|_{1} \leq \frac{\alpha^{n}}{1-\alpha}\left\|w_{0}-w_{1}\right\|_{1}, \quad \forall n \in \mathbb{N}
\end{aligned}
$$

Proof Define a mapping $H: B C(S) \rightarrow B C(S)$ by

$$
\begin{aligned}
H h(x)= & \lambda \underset{y \in D}{\operatorname{opt}}\{u(x, y) \operatorname{opt}\{p(x, y), h(a(x, y))\}\} \\
& +(1-\lambda) \underset{y \in D}{\operatorname{opt}}\{v(x, y) \operatorname{opt}\{q(x, y), h(b(x, y))\} \\
& +t(x, y) \operatorname{opt}\{r(x, y), h(c(x, y))\}\}, \quad \forall(x, h) \in S \times B C(S) .
\end{aligned}
$$

Firstly, we show that $H$ is a self-mapping in $B C(S)$. Let $\left(x_{0}, h\right) \in S \times B C(S)$ and $\varepsilon>0$. It follows from (C1), (C3) and the compactness of $S$ that there exist constants $M>0, \delta>0$ and $\delta_{1}>0$ such that

$$
\begin{aligned}
& \sup _{(x, y) \in S \times D} \max \{|h(x)|,|h(a(x, y))|,|h(b(x, y))|,|h(c(x, y))|,|p(x, y)|,|q(x, y)|,|r(x, y)|\} \\
& \quad \leq M \\
& \max \left\{\left|u(x, y)-u\left(x_{0}, y\right)\right|,\left|v(x, y)-v\left(x_{0}, y\right)\right|+\left|t(x, y)-t\left(x_{0}, y\right)\right|\right\}<\frac{\varepsilon}{2 M} \\
& \quad \forall(x, y) \in S \times D \text { with }\left\|x-x_{0}\right\|<\delta \\
& \max \left\{\left|p(x, y)-p\left(x_{0}, y\right)\right|,\left|q(x, y)-q\left(x_{0}, y\right)\right|,\left|r(x, y)-r\left(x_{0}, y\right)\right|\right\}<\frac{\varepsilon}{2} \\
& \quad \forall(x, y) \in S \times D \text { with }\left\|x-x_{0}\right\|<\delta \\
& \left|h\left(x_{1}\right)-h\left(x_{2}\right)\right|<\frac{\varepsilon}{2}, \quad \forall x_{1}, x_{2} \in S \text { with }\left\|x_{1}-x_{2}\right\|<\delta_{1} ; \\
& \max \left\{\left\|a(x, y)-a\left(x_{0}, y\right)\right\|,\left\|b(x, y)-b\left(x_{0}, y\right)\right\|,\left\|c(x, y)-c\left(x_{0}, y\right)\right\|\right\}<\delta_{1} \\
& \quad \forall(x, y) \in S \times D \text { with }\left\|x-x_{0}\right\|<\delta .
\end{aligned}
$$

On account of (C2), (3.3)-(3.8), Lemmas 2.1 and 2.2, we infer that

$$
\begin{aligned}
& \left|H h(x)-H h\left(x_{0}\right)\right| \\
& =\mid \lambda \underset{y \in D}{\operatorname{opt}}\{u(x, y) \operatorname{opt}\{p(x, y), h(a(x, y))\}\} \\
& +(1-\lambda) \underset{y \in D}{\operatorname{opt}}\{v(x, y) \operatorname{opt}\{q(x, y), h(b(x, y))\}+t(x, y) \operatorname{opt}\{r(x, y), h(c(x, y))\}\}
\end{aligned}
$$




$$
\begin{aligned}
& -\lambda \underset{y \in D}{\operatorname{opt}}\left\{u\left(x_{0}, y\right) \operatorname{opt}\left\{p\left(x_{0}, y\right), h\left(a\left(x_{0}, y\right)\right)\right\}\right\} \\
& -(1-\lambda) \underset{y \in D}{\operatorname{opt}}\left\{v\left(x_{0}, y\right) \operatorname{opt}\left\{q\left(x_{0}, y\right), h\left(b\left(x_{0}, y\right)\right)\right\}+t\left(x_{0}, y\right) \operatorname{opt}\left\{r\left(x_{0}, y\right), h\left(c\left(x_{0}, y\right)\right)\right\}\right\} \mid \\
& \leq \lambda\left|\operatorname{opt}_{y \in D}\{u(x, y) \operatorname{opt}\{p(x, y), h(a(x, y))\}\}-\underset{y \in D}{\operatorname{opt}}\left\{u\left(x_{0}, y\right) \operatorname{opt}\{p(x, y), h(a(x, y))\}\right\}\right| \\
& +\lambda\left|\operatorname{opt}_{y \in D}\left\{u\left(x_{0}, y\right) \operatorname{opt}\{p(x, y), h(a(x, y))\}\right\}-\underset{y \in D}{\operatorname{opt}}\left\{u\left(x_{0}, y\right) \operatorname{opt}\left\{p\left(x_{0}, y\right), h\left(a\left(x_{0}, y\right)\right)\right\}\right\}\right| \\
& +(1-\lambda) \mid \operatorname{opt}_{y \in D}\{v(x, y) \operatorname{opt}\{q(x, y), h(b(x, y))\}+t(x, y) \operatorname{opt}\{r(x, y), h(c(x, y))\}\} \\
& -\operatorname{opt}_{y \in D}\left\{v\left(x_{0}, y\right) \operatorname{opt}\{q(x, y), h(b(x, y))\}+t\left(x_{0}, y\right) \operatorname{opt}\{r(x, y), h(c(x, y))\}\right\} \mid \\
& +(1-\lambda) \operatorname{opt}_{y \in D}\left\{v\left(x_{0}, y\right) \operatorname{opt}\{q(x, y), h(b(x, y))\}+t\left(x_{0}, y\right) \operatorname{opt}\{r(x, y), h(c(x, y))\}\right\} \\
& -\underset{y \in D}{\operatorname{opt}}\left\{v\left(x_{0}, y\right) \operatorname{opt}\left\{q\left(x_{0}, y\right), h\left(b\left(x_{0}, y\right)\right)\right\}+t\left(x_{0}, y\right) \operatorname{opt}\left\{r\left(x_{0}, y\right), h\left(c\left(x_{0}, y\right)\right)\right\}\right\} \mid \\
& \leq \lambda \sup _{y \in D}\left\{\left|u(x, y)-u\left(x_{0}, y\right)\right| \max \{|p(x, y)|,|h(a(x, y))|\}\right\} \\
& +\lambda \sup _{y \in D}\left\{\left|u\left(x_{0}, y\right)\right|\left|\operatorname{opt}\{p(x, y), h(a(x, y))\}-\operatorname{opt}\left\{p\left(x_{0}, y\right), h\left(a\left(x_{0}, y\right)\right)\right\}\right|\right\} \\
& +(1-\lambda) \sup _{y \in D}\left\{\left|v(x, y)-v\left(x_{0}, y\right)\right| \max \{|q(x, y)|,|h(b(x, y))|\}\right. \\
& \left.+\left|t(x, y)-t\left(x_{0}, y\right)\right| \max \{|r(x, y)|,|h(c(x, y))|\}\right\} \\
& +(1-\lambda) \sup _{y \in D}\left\{\left|v\left(x_{0}, y\right)\right|\left|\operatorname{opt}\{q(x, y), h(b(x, y))\}-\operatorname{opt}\left\{q\left(x_{0}, y\right), h\left(b\left(x_{0}, y\right)\right)\right\}\right|\right. \\
& \left.+\left|t\left(x_{0}, y\right)\right|\left|\operatorname{opt}\{r(x, y), h(c(x, y))\}-\operatorname{opt}\left\{r\left(x_{0}, y\right), h\left(c\left(x_{0}, y\right)\right)\right\}\right|\right\} \\
& \leq \lambda M \sup _{y \in D}\left|u(x, y)-u\left(x_{0}, y\right)\right| \\
& +\lambda \alpha \sup _{y \in D} \max \left\{\left|p(x, y)-p\left(x_{0}, y\right)\right|,\left|h(a(x, y))-h\left(a\left(x_{0}, y\right)\right)\right|\right\} \\
& +(1-\lambda) M \sup _{y \in D}\left\{\left|v(x, y)-v\left(x_{0}, y\right)\right|+\left|t(x, y)-t\left(x_{0}, y\right)\right|\right\} \\
& +(1-\lambda) \sup _{y \in D}\left\{( | v ( x _ { 0 } , y ) | + | t ( x _ { 0 } , y ) | ) \operatorname { m a x } \left\{\left|q(x, y)-q\left(x_{0}, y\right)\right|,\right.\right. \\
& \left.\left.\left|h(b(x, y))-h\left(b\left(x_{0}, y\right)\right)\right|,\left|r(x, y)-r\left(x_{0}, y\right)\right|,\left|h(c(x, y))-h\left(c\left(x_{0}, y\right)\right)\right|\right\}\right\} \\
& <\lambda M \frac{\varepsilon}{2 M}+\lambda \alpha \frac{\varepsilon}{2}+(1-\lambda) M \frac{\varepsilon}{2 M}+(1-\lambda) \alpha \frac{\varepsilon}{2} \\
& <\varepsilon, \quad \forall x \in S \text { with }\left\|x-x_{0}\right\|<\delta
\end{aligned}
$$

and

$|H h(x)|$

$$
=\mid \lambda \underset{y \in D}{\operatorname{opt}}\{u(x, y) \operatorname{opt}\{p(x, y), h(a(x, y))\}\}
$$




$$
\begin{aligned}
& +(1-\lambda) \operatorname{opt}_{y \in D}\{v(x, y) \operatorname{opt}\{q(x, y), h(b(x, y))\}+t(x, y) \operatorname{opt}\{r(x, y), h(c(x, y))\}\} \mid \\
\leq & \lambda \sup _{y \in D}\{|u(x, y)||\operatorname{opt}\{p(x, y), h(a(x, y))\}|\} \\
& +(1-\lambda) \sup _{y \in D}\{|v(x, y)||\operatorname{opt}\{q(x, y), h(b(x, y))\}|+|t(x, y)||\operatorname{opt}\{r(x, y), h(c(x, y))\}|\} \\
\leq & \lambda \alpha \sup _{y \in D} \max \{|p(x, y)|,|h(a(x, y))|\} \\
& +(1-\lambda) \sup _{y \in D}\{[|v(x, y)|+|t(x, y)|] \max \{|q(x, y)|,|r(x, y)|,|h(b(x, y))|,|h(c(x, y))|\}\} \\
\leq & \lambda \alpha M+(1-\lambda) \alpha M \\
= & \alpha M, \quad \forall x \in S,
\end{aligned}
$$

which yields that $H h$ is bounded and continuous in $S$. That is, $H$ maps $B C(S)$ into $B C(S)$.

Secondly, we show that $H$ is a contraction mapping in $B C(S)$. Given $\varepsilon>0$. In view of (3.3), Lemmas 2.1 and 2.2, we get that

$$
\begin{aligned}
& |H h(x)-H g(x)| \\
& =\mid \lambda \underset{y \in D}{\lambda \operatorname{opt}}\{u(x, y) \operatorname{opt}\{p(x, y), h(a(x, y))\}\} \\
& \quad+(1-\lambda) \operatorname{opt}_{y \in D}\{v(x, y) \operatorname{opt}\{q(x, y), h(b(x, y))\}+t(x, y) \operatorname{opt}\{r(x, y), h(c(x, y))\}\} \\
& \quad-\lambda \underset{y \in D}{\operatorname{opt}}\{u(x, y) \operatorname{opt}\{p(x, y), g(a(x, y))\}\} \\
& \quad-(1-\lambda) \operatorname{opt}_{y \in D}\{v(x, y) \operatorname{opt}\{q(x, y), g(b(x, y))\}+t(x, y) \operatorname{opt}\{r(x, y), g(c(x, y))\}\} \mid \\
& \leq \lambda \sup _{y \in D}\{|u(x, y)||\operatorname{opt}\{p(x, y), h(a(x, y))\}-\operatorname{opt}\{p(x, y), g(a(x, y))\}|\} \\
& \quad+(1-\lambda) \sup _{y \in D}\{|v(x, y)||\operatorname{opt}\{q(x, y), h(b(x, y))\}-\operatorname{opt}\{q(x, y), g(b(x, y))\}| \\
& \quad+|t(x, y)||\operatorname{opt}\{r(x, y), h(c(x, y))\}-\operatorname{opt}\{r(x, y), g(c(x, y))\}|\} \\
& \leq \lambda \alpha \sup _{y \in D}\{|h(a(x, y))-g(a(x, y))|\}+(1-\lambda) \sup _{y \in D}\{[|v(x, y)|+|t(x, y)|] \\
& \quad \times \max \{|h(b(x, y))-g(b(x, y))|,|h(c(x, y))-g(c(x, y))|\}\} \\
& \leq \alpha\|h-g\|_{1}, \quad \forall x \in S, h, g \in B C(S),
\end{aligned}
$$

which gives that

$$
\|H h-H g\|_{1} \leq \alpha\|h-g\|_{1}, \quad \forall h, g \in B C(S),
$$

that is, $H$ is a contraction mapping in $B C(S)$. Thus the Banach fixed point theorem yields that $H$ has a unique fixed point $w \in B C(S)$, which is a unique solution of functional equation (1.7) in $B C(S)$. 
Thirdly, we show (C4). Note that

$$
\begin{aligned}
w(x)= & \lambda \underset{y \in D}{\operatorname{opt}}\{u(x, y) \operatorname{opt}\{p(x, y), w(a(x, y))\}\} \\
& +(1-\lambda) \underset{y \in D}{\operatorname{opt}}\{v(x, y) \operatorname{opt}\{q(x, y), w(b(x, y))\} \\
& +t(x, y) \operatorname{opt}\{r(x, y), w(c(x, y))\}\}, \quad \forall x \in S,
\end{aligned}
$$

which together with (3.1), (3.3) and (3.9) yields that

$$
\begin{aligned}
\left\|w_{n}-w\right\|_{1} & =\sup _{x \in S}\left|w_{n}(x)-w(x)\right|=\sup _{x \in S}\left|H w_{n-1}(x)-H w(x)\right|=\left\|H w_{n-1}-H w\right\| \\
& \leq \alpha\left\|w_{n-1}-w\right\|_{1} \leq \cdots \leq \alpha^{n}\left\|w_{0}-w\right\|_{1}, \quad \forall n \in \mathbb{N}
\end{aligned}
$$

which guarantees that the sequence $\left\{w_{n}\right\}_{n \in \mathbb{N}_{0}}$ converges to $w$. Similarly, we conclude that

$$
\begin{aligned}
\left\|w_{n}-w_{n+m}\right\|_{1} & \leq \sum_{i=n}^{n+m-1}\left\|w_{i}-w_{i+1}\right\|_{1}=\sum_{i=n}^{n+m-1}\left\|H w_{i-1}-H w_{i}\right\|_{1} \leq \sum_{i=n}^{n+m-1} \alpha\left\|w_{i-1}-w_{i}\right\|_{1} \\
& \leq \cdots \leq \sum_{i=n}^{n+m-1} \alpha^{i}\left\|w_{0}-w_{1}\right\|_{1} \leq \frac{\alpha^{n}}{1-\alpha}\left\|w_{0}-w_{1}\right\|_{1}, \quad \forall(n, m) \in \mathbb{N} \times \mathbb{N} .
\end{aligned}
$$

Letting $m \rightarrow \infty$ in the above inequalities, we infer that (3.2) holds. This completes the proof.

Using the proof of Theorem 3.1, we have the following.

Theorem 3.2 Let $\alpha \in(0,1)$ and $\lambda \in[0,1]$. Let $p, q, r, u, v, t: S \times D \rightarrow \mathbb{R}$ and $a, b, c: S \times$ $D \rightarrow S$ satisfy (C1) and (C2). Then functional equation (1.7) possesses a unique solution $w \in B(S)$ and for each $w_{0} \in B(S)$, the sequence $\left\{w_{n}\right\}_{n \in \mathbb{N}_{0}}$ defined by (3.1) converges to $w$ and satisfies (C4).

Example 3.3 Consider the functional equation

$$
\begin{aligned}
f(x)= & \lambda \underset{y \in \mathbb{R}^{+}}{\operatorname{opt}}\left\{\frac{\cos \left(x^{9}+y^{18}\right)}{y^{2}+2} \text { opt }\left\{\frac{x^{56}}{x^{31}+y^{5}+1}, f\left(\sin ^{8}\left(x^{2}-y^{35}\right)\right)\right\}\right\} \\
& +(1-\lambda) \operatorname{opt}_{y \in \mathbb{R}^{+}}\left\{\frac{x^{2} \sin \left(y^{14}\right)}{2(x+1)^{2}+y^{3}} \text { opt }\left\{\frac{x^{25} \ln \left(1+x^{2}\right)}{x^{2}+y^{3}+1}, f\left(\frac{x^{6}}{x^{2}+y^{2}+1}\right)\right\}\right. \\
& \left.+\frac{\sqrt{x+1}}{3 \sqrt{x+2}+y^{2}} \text { opt }\left\{\frac{x^{10} \cos ^{6}\left(y^{7}-y\right)}{y^{3}+y^{2}+1}, f\left(\frac{x^{7} y}{x^{3}+y^{2}+1}\right)\right\}\right\}, \quad \forall x \in[0,40] .
\end{aligned}
$$

Put $X=Y=\mathbb{R}, S=[0,40], D=\mathbb{R}^{+}, \lambda \in[0,1], \alpha=\frac{5}{6}$. Let $p, q, r, u, v, t: S \times D \rightarrow \mathbb{R}$ and $a, b, c: S \times D \rightarrow S$ be defined by

$$
\begin{aligned}
& p(x, y)=\frac{x^{56}}{x^{31}+y^{5}+1}, \quad q(x, y)=\frac{x^{25} \ln \left(1+x^{2}\right)}{x^{2}+y^{3}+1}, \quad r(x, y)=\frac{x^{10} \cos ^{6}\left(y^{7}-y\right)}{y^{3}+y^{2}+1}, \\
& u(x, y)=\frac{\cos \left(x^{9}+y^{18}\right)}{y^{2}+2}, \quad v(x, y)=\frac{x^{2} \sin \left(y^{14}\right)}{2(x+1)^{2}+y^{3}}, \quad t(x, y)=\frac{\sqrt{x+1}}{3 \sqrt{x+2}+y^{2}},
\end{aligned}
$$




$$
\begin{aligned}
& a(x, y)=\sin ^{8}\left(x^{2}-y^{35}\right), \quad b(x, y)=\frac{x^{6}}{x^{2}+y^{2}+1}, \quad c(x, y)=\frac{x^{7} y}{x^{3}+y^{2}+1}, \\
& \forall(x, y) \in S \times D .
\end{aligned}
$$

It is easy to see that the conditions of Theorem 3.1 are satisfied. It follows from Theorem 3.1 that functional equation (3.11) possesses a unique solution $w \in B C(S)$ and (C4) holds.

Example 3.4 Consider the functional equation

$$
\begin{aligned}
f(x)= & \lambda \text { opt }\left\{\frac{x y^{2} \sin ^{45}\left(x^{9} y^{7}\right)}{x^{2}+y^{4}+1} \operatorname{opt}\left\{\sin ^{3}\left(x y^{5}\right), f\left(x^{59} \sqrt{x^{4}+y^{24}}\right)\right\}\right\} \\
& +(1-\lambda) \text { opt }\left\{\frac{x^{3} \arctan \left(x^{15} y^{21}\right)}{2 \pi x^{3}+y^{2}+1} \operatorname{opt}\left\{\cos ^{9}\left(x^{6} y^{3}(x+y)\right), f\left(x^{2} y^{6}\right)\right\}\right. \\
& \left.+\frac{2 x^{4}-\sin ^{2}(x y)}{3 x^{4}+\cos ^{4}\left(x^{8} y^{6}\right)} \operatorname{opt}\left\{\frac{x^{3}-y^{2}}{(x+1)^{4}+y^{2}}, f\left(x^{35}-y^{47}-x y\right)\right\}\right\}, \quad \forall x \in \mathbb{R}^{+} .
\end{aligned}
$$

Set $X=Y=\mathbb{R}, S=\mathbb{R}^{+}, D=\mathbb{R}_{-}, \lambda \in[0,1], \alpha=\frac{11}{12}$. Let $p, q, r, u, v, t: S \times D \rightarrow \mathbb{R}$ and $a, b, c$ : $S \times D \rightarrow S$ be defined by

$$
\begin{aligned}
& p(x, y)=\sin ^{3}\left(x y^{5}\right), \quad q(x, y)=\cos ^{9}\left(x^{6} y^{3}(x+y)\right), \quad r(x, y)=\frac{x^{3}-y^{2}}{(x+1)^{4}+y^{2}}, \\
& u(x, y)=\frac{x y^{2} \sin ^{45}\left(x^{9} y^{7}\right)}{x^{2}+y^{4}+1}, \quad v(x, y)=\frac{x^{3} \arctan \left(x^{15} y^{21}\right)}{2 \pi x^{3}+y^{2}+1}, \\
& t(x, y)=\frac{2 x^{4}-\sin ^{2}(x y)}{3 x^{4}+\cos ^{4}\left(x^{8} y^{6}\right)}, \quad a(x, y)=x^{59} \sqrt{x^{4}+y^{24}}, \quad b(x, y)=x^{2} y^{6}, \\
& c(x, y)=x^{35}-y^{47}-x y, \quad \forall(x, y) \in S \times D .
\end{aligned}
$$

It is clear that the conditions of Theorem 3.2 are fulfilled. Thus Theorem 3.2 guarantees that functional equation (3.12) possesses a unique solution $w \in B(S)$, which satisfies (C4).

Next we prove the existence, uniqueness and iterative approximation of solutions for functional equation (1.7) in the complete metric space $B B(S)$ by using Liu-Ume-Kang fixed point theorem.

Theorem 3.5 Let $\alpha \in(0,1), \lambda \in[0,1], p, q, r, u, v, t: S \times D \rightarrow \mathbb{R}$ and $a, b, c: S \times D \rightarrow S$ satisfy that

(C5) $p, q$ and $r$ are bounded on $\bar{B}(0, k) \times D, \forall k \in \mathbb{N}$;

(C6) $\sup _{(x, y) \in \bar{B}(0, k) \times D} \max \{|u(x, y)|,|v(x, y)|+|t(x, y)|\} \leq \alpha, \forall k \in \mathbb{N}$;

(C7) $\sup _{(x, y) \in \bar{B}(0, k) \times D} \max \{\|a(x, y)\|,\|b(x, y)\|,\|c(x, y)\|\} \leq k, \forall k \in \mathbb{N}$.

Then functional equation (1.7) possesses a unique solution $w \in B B(S)$ such that

(C8) for each $w_{0} \in B B(S)$, the sequence $\left\{w_{n}\right\}_{n \in \mathbb{N}_{0}}$ defined by

$$
\begin{aligned}
w_{n}(x)= & \lambda \underset{y \in D}{\operatorname{opt}}\left\{u(x, y) \operatorname{opt}\left\{p(x, y), w_{n-1}(a(x, y))\right\}\right\} \\
& +(1-\lambda) \underset{y \in D}{\operatorname{opt}}\left\{v(x, y) \operatorname{opt}\left\{q(x, y), w_{n-1}(b(x, y))\right\}\right.
\end{aligned}
$$




$$
\begin{aligned}
& \left.+t(x, y) \operatorname{opt}\left\{r(x, y), w_{n-1}(c(x, y))\right\}\right\}, \\
& \forall(x, k, n) \in \bar{B}(0, k) \times \mathbb{N} \times \mathbb{N}
\end{aligned}
$$

converges to $w$ and has the following error estimates:

$$
\begin{aligned}
& d_{k}\left(w_{n}, w\right) \leq \alpha^{n} d_{k}\left(w_{0}, w\right) \text { and } \\
& d_{k}\left(w_{n}, w\right) \leq \frac{\alpha^{n}}{1-\alpha} d_{k}\left(w_{0}, w_{1}\right), \quad \forall(k, n) \in \mathbb{N} \times \mathbb{N} .
\end{aligned}
$$

Proof Define a mapping $H: B B(S) \rightarrow B B(S)$ by

$$
\begin{aligned}
H h(x)= & \lambda \underset{y \in D}{\operatorname{opt}}\{u(x, y) \operatorname{opt}\{p(x, y), h(a(x, y))\}\} \\
& +(1-\lambda) \underset{y \in D}{\operatorname{opt}}\{v(x, y) \operatorname{opt}\{q(x, y), h(b(x, y))\} \\
& +t(x, y) \operatorname{opt}\{r(x, y), h(c(x, y))\}\}, \quad \forall(x, k, h) \in \bar{B}(0, k) \times \mathbb{N} \times B B(S) .
\end{aligned}
$$

It follows from (C5) and (C7) that for each $(k, h) \in \mathbb{N} \times B B(S)$, there exist $\gamma(k)>0$ and $\beta(k, h)>0$ such that

$$
\begin{aligned}
& \sup _{(x, y) \in \bar{B}(0, k) \times D} \max \{|p(x, y)|,|q(x, y)|,|r(x, y)|\} \leq \gamma(k) ; \\
& \sup _{(x, y) \in \bar{B}(0, k) \times D} \max \{|h(a(x, y))|,|h(b(x, y))|,|h(c(x, y))|\} \leq \beta(k, h),
\end{aligned}
$$

which together with (C6), (3.15) and Lemma 2.1 gives that

$$
\begin{aligned}
|H h(x)| & \\
= & \mid \lambda \underset{y \in D}{\operatorname{opt}}\{u(x, y) \operatorname{opt}\{p(x, y), h(a(x, y))\}\} \\
& +(1-\lambda) \operatorname{opt}_{y \in D}\{v(x, y) \operatorname{opt}\{q(x, y), h(b(x, y))\} \\
& +t(x, y) \operatorname{opt}\{r(x, y), h(c(x, y))\}\} \mid \\
\leq & \lambda \sup _{y \in D}\{|u(x, y)| \max \{|p(x, y)|,|h(a(x, y))|\}\} \\
& +(1-\lambda) \sup _{y \in D}\{|v(x, y)| \max \{|q(x, y)|,|h(b(x, y))|\} \\
& +|t(x, y)| \max \{|r(x, y)|,|h(c(x, y))|\}\} \\
\leq & \lambda \alpha \max \{\gamma(k), \beta(k, h)\}+(1-\lambda) \max \{\gamma(k), \beta(k, h)\} \sup _{y \in D}(|v(x, y)|+|t(x, y)|) \\
\leq & \lambda \alpha \max \{\gamma(k), \beta(k, h)\}+(1-\lambda) \alpha \max \{\gamma(k), \beta(k, h)\} \\
= & \alpha \max \{\gamma(k), \beta(k, h)\}, \quad \forall(x, k, h) \in \bar{B}(0, k) \times \mathbb{N} \times B B(S),
\end{aligned}
$$


which means that $H$ is a self-mapping in $B B(S)$. By virtue of (3.15), (C6), (C7), Lemmas 2.1 and 2.2, we get that

$$
\begin{aligned}
& |H h(x)-H g(x)| \\
& =\mid \lambda \underset{y \in D}{\operatorname{opt}}\{u(x, y) \operatorname{opt}\{p(x, y), h(a(x, y))\}\} \\
& \quad+(1-\lambda) \operatorname{opt}_{y \in D}\{v(x, y) \operatorname{opt}\{q(x, y), h(b(x, y))\}+t(x, y) \operatorname{opt}\{r(x, y), h(c(x, y))\}\} \\
& \quad-\lambda \operatorname{opt}_{y \in D}\{u(x, y) \operatorname{opt}\{p(x, y), g(a(x, y))\}\} \\
& \quad-(1-\lambda) \operatorname{opt}_{y \in D}\{v(x, y) \operatorname{opt}\{q(x, y), g(b(x, y))\}+t(x, y) \operatorname{opt}\{r(x, y), g(c(x, y))\}\} \mid \\
& \leq \lambda \sup _{y \in D}\{|u(x, y)||\operatorname{opt}\{p(x, y), h(a(x, y))\}-\operatorname{opt}\{p(x, y), g(a(x, y))\}|\} \\
& \quad+(1-\lambda) \sup _{y \in D}\{|v(x, y)||\operatorname{opt}\{q(x, y), h(b(x, y))\}-\operatorname{opt}\{q(x, y), g(b(x, y))\}| \\
& \quad+|t(x, y)||\operatorname{opt}\{r(x, y), h(c(x, y))\}-\operatorname{opt}\{r(x, y), g(c(x, y))\}|\} \\
& \left.\leq \lambda \alpha d_{k}(h, g)+(1-\lambda) \sup _{y \in D}\{|v(x, y)|+\mid t(x, y)]\right\} d_{k}(h, g) \\
& \leq \alpha d_{k}(h, g), \quad(x, k, h, g) \in \bar{B}(0, k) \times \mathbb{N} \times B B(S) \times B B(S),
\end{aligned}
$$

which yields that

$$
d_{k}(H h, H g) \leq \alpha d_{k}(h, g), \quad \forall(k, h, g) \in \mathbb{N} \times B B(S) \times B B(S) .
$$

Put $\varphi(t)=\alpha t$ for all $t \in \mathbb{R}^{+}$. It follows from (3.16) and Lemma 2.3 that $H$ has a unique fixed point $w \in B B(S)$, which is also a unique solution of functional equation (1.7). In light of (3.13), (3.15) and (3.16), we obtain that

$$
\begin{aligned}
d_{k}\left(w_{n}, w\right) & =d_{k}\left(H w_{n-1}, H w\right) \leq \alpha d_{k}\left(w_{n-1}, w\right) \leq \cdots \\
& \leq \alpha^{n} d_{k}\left(w_{0}, w\right), \quad \forall(k, n) \in \mathbb{N} \times \mathbb{N}
\end{aligned}
$$

and

$$
\begin{aligned}
d_{k}\left(w_{n}, w_{n+m}\right) & \leq \sum_{i=n}^{n+m-1} d_{k}\left(w_{i}, w_{i+1}\right)=\sum_{i=n}^{n+m-1} d_{k}\left(H w_{i-1}, H w_{i}\right) \\
& \leq \sum_{i=n}^{n+m-1} \alpha d_{k}\left(w_{i-1}, w_{i}\right) \leq \sum_{i=n}^{n+m-1} \alpha^{i} d_{k}\left(w_{0}, w_{1}\right) \\
& \leq \frac{\alpha^{n}}{1-\alpha} d_{k}\left(w_{0}, w_{1}\right), \quad \forall(k, n, m) \in \mathbb{N} \times \mathbb{N} \times \mathbb{N} .
\end{aligned}
$$

Clearly (3.17) means that $\left\{w_{n}\right\}_{n \in \mathbb{N}_{0}}$ converges to $w$. Thus (3.14) follows from (3.17) and (3.18) by letting $m \rightarrow \infty$. This completes the proof. 
Remark 3.6 Theorem 3.5 extends Theorem 3.4 in [5] and Corollaries 2.2 and 2.3 in [11]. The example below shows that Theorem 3.5 extends substantially the corresponding results in $[5,11]$.

Example 3.7 Consider the functional equation

$$
\begin{aligned}
f(x)= & \lambda \underset{y \in \mathbb{R}^{+}}{\operatorname{opt}}\left\{\frac{x^{3} \cos ^{75}\left(x^{6} y^{98}\right)}{3(x+1)^{3}+y^{5}} \text { opt }\left\{\frac{x^{69}}{\left(x^{5}-y^{6}\right)^{4}+1}, f\left(\frac{x^{7} \sin ^{4}(x y)}{x^{6}+x y^{3}+1}\right)\right\}\right\} \\
& +(1-\lambda) \underset{y \in \mathbb{R}^{+}}{\operatorname{opt}}\left\{\frac{\sin ^{9}\left(x^{8} y^{3}\right)}{x y^{2}+5} \text { opt }\left\{\frac{x^{120} y^{7}}{x^{9} y^{7}+1}, f\left(\frac{x^{6} y^{4} \cos ^{8}\left(x^{3} y^{9}\right)}{x^{5} y^{4}+1}\right)\right\}\right. \\
& \left.+\frac{x^{2} y}{x^{4}+(y+1)^{2}} \text { opt }\left\{\frac{x^{57} y^{2}}{x^{10}+y^{4}+1}, f\left(\frac{\ln \left(1+x^{15} y^{23}\right)}{(x+1)^{14}\left(y^{23}+1\right)}\right)\right\}\right\}, \quad \forall x \in \mathbb{R}^{+} .
\end{aligned}
$$

Put $X=Y=\mathbb{R}, S=D=\mathbb{R}^{+}, \lambda \in[0,1]$ and $\alpha=\frac{7}{10}$. Let $p, q, r, u, v, t: S \times D \rightarrow \mathbb{R}$ and $a, b, c$ : $S \times D \rightarrow S$ be defined by

$$
\begin{aligned}
& p(x, y)=\frac{x^{69}}{\left(x^{5}-y^{6}\right)^{4}+1}, \quad q(x, y)=\frac{x^{120} y^{7}}{x^{9} y^{7}+1}, \quad r(x, y)=\frac{x^{57} y^{2}}{x^{10}+y^{4}+1}, \\
& u(x, y)=\frac{x^{3} \cos ^{75}\left(x^{6} y^{98}\right)}{3(x+1)^{3}+y^{5}}, \quad v(x, y)=\frac{\sin ^{9}\left(x^{8} y^{3}\right)}{x y^{2}+5}, \quad t(x, y)=\frac{x^{2} y}{x^{4}+(y+1)^{2}}, \\
& a(x, y)=\frac{x^{7} \sin ^{4}(x y)}{x^{6}+x y^{3}+1}, \quad b(x, y)=\frac{x^{6} y^{4} \cos ^{8}\left(x^{3} y^{9}\right)}{x^{5} y^{4}+1}, \\
& c(x, y)=\frac{\ln \left(1+x^{15} y^{23}\right)}{(x+1)^{14}\left(y^{23}+1\right)}, \quad \forall(x, y) \in S \times D .
\end{aligned}
$$

It is clear that the conditions of Theorem 3.5 are satisfied. It follows from Theorem 3.5 that functional equation (3.19) possesses a unique solution $w \in B B(S)$, which satisfies (C8). But Theorem 3.4 in [5] and Corollaries 2.2 and 2.3 in [11] are unapplicable to functional equation (3.19).

Next we discuss the behaviors of solutions and iterative algorithms for functional equation (1.7) in the complete metric space $B B(S)$.

Theorem 3.8 Let $\lambda \in[0,1],(\varphi, \psi) \in \Phi_{2}, p, q, r, u, v, t: S \times D \rightarrow \mathbb{R}$ and $a, b, c: S \times D \rightarrow S$ satisfy that

(C9) $\sup _{(x, y) \in \bar{B}(0, k) \times D} \max \{|p(x, y)|,|q(x, y)|,|r(x, y)|\} \leq \psi(\|x\|), \forall k \in \mathbb{N}$;

(C10) $\sup _{(x, y) \in \bar{B}(0, k) \times D} \max \{|u(x, y)|,|v(x, y)|+|t(x, y)|\} \leq 1, \forall k \in \mathbb{N}$;

(C11) $\sup _{(x, y) \in \bar{B}(0, k) \times D} \max \{\|a(x, y)\|,\|b(x, y)\|,\|c(x, y)\|\} \leq \varphi(\|x\|), \forall k \in \mathbb{N}$.

Then functional equation (1.7) possesses a solution $w \in B B(S)$ such that

(C12) for each $w_{0} \in B B(S)$ with $\left|w_{0}(x)\right| \leq \psi(\|x\|), \forall(x, k) \in \bar{B}(0, k) \times \mathbb{N}$, the sequence $\left\{w_{n}\right\}_{n \in \mathbb{N}_{0}}$ defined by (3.13) converges to $w$ and $d_{k}\left(w_{n}, w\right) \leq \sum_{j=n-1}^{\infty} \psi\left(\varphi^{j}(k)\right)$, $\forall(k, n) \in \mathbb{N} \times \mathbb{N}$

(C13) $|w(x)| \leq \sum_{n=0}^{\infty} \psi\left(\varphi^{n}(\|x\|)\right), \forall(x, k) \in \bar{B}(0, k) \times \mathbb{N}$;

(C14) $\lim _{n \rightarrow \infty} w\left(x_{n}\right)=0$ for any $\left(x_{0}, k\right) \in \bar{B}(0, k) \times \mathbb{N},\left\{y_{n}\right\}_{n \in \mathbb{N}} \subset D$ and $x_{n} \in\left\{a\left(x_{n-1}, y_{n}\right), b\left(x_{n-1}, y_{n}\right), c\left(x_{n-1}, y_{n}\right)\right\}, \forall n \in \mathbb{N} ;$

(C15) $w$ is a unique solution of functional equation (1.7) relative to (C14). 
Proof Define a mapping $H: B B(S) \rightarrow B B(S)$ by

$$
H h(x)=\lambda A h(x)+(1-\lambda) B h(x), \quad \forall(x, k, h) \in \bar{B}(0, k) \times \mathbb{N} \times B B(S),
$$

where

$$
\begin{aligned}
& A h(x)=\underset{y \in D}{\operatorname{opt}}\{u(x, y) \operatorname{opt}\{p(x, y), h(a(x, y))\}\}, \\
& B h(x)=\underset{y \in D}{\operatorname{opt}}\{v(x, y) \operatorname{opt}\{q(x, y), h(b(x, y))\}+t(x, y) \operatorname{opt}\{r(x, y), h(c(x, y))\}\}, \\
& \forall(x, k, h) \in \bar{B}(0, k) \times \mathbb{N} \times B B(S) .
\end{aligned}
$$

Note that (C9) and (C11) imply (C5) and (C7) by $(\varphi, \psi) \in \Phi_{2}$, respectively. Similar to the proof of Theorem 3.5, by (C10) we conclude that the mapping $H$ maps $B B(S)$ into $B B(S)$ and satisfies that

$$
d_{k}(H h, H g) \leq d_{k}(h, g), \quad \forall(h, g, k) \in B B(S) \times B B(S) \times \mathbb{N},
$$

which yields that

$$
\begin{aligned}
d(H h, H g) & =\sum_{k=1}^{\infty} \frac{1}{2^{k}} \cdot \frac{d_{k}(H h, H g)}{1+d_{k}(H h, H g)} \leq \sum_{k=1}^{\infty} \frac{1}{2^{k}} \cdot \frac{d_{k}(h, g)}{1+d_{k}(h, g)} \\
& =d(h, g), \quad \forall(h, g) \in B B(S) \times B B(S),
\end{aligned}
$$

that is, the mapping $H$ is nonexpansive in $B B(S)$.

Now we show that for each $n \in \mathbb{N}_{0}$,

$$
\left|w_{n}(x)\right| \leq \sum_{j=0}^{n} \psi\left(\varphi^{j}(\|x\|)\right), \quad \forall(x, k) \in \bar{B}(0, k) \times \mathbb{N} .
$$

It is easy to see that (3.23) holds for $n=0$. Assume that (3.23) holds for some $n \in \mathbb{N}_{0}$. In terms of (C9), (C11), (C12), (3.13), $(\varphi, \psi) \in \Phi_{2}$ and Lemma 2.1, we gain that

$$
\begin{aligned}
& \left|w_{n+1}(x)\right| \\
& =\mid \lambda \underset{y \in D}{\operatorname{opt}}\left\{u(x, y) \operatorname{opt}\left\{p(x, y), w_{n}(a(x, y))\right\}\right\} \\
& +(1-\lambda) \underset{y \in D}{\operatorname{opt}}\left\{v(x, y) \operatorname{opt}\left\{q(x, y), w_{n}(b(x, y))\right\}+t(x, y) \operatorname{opt}\left\{r(x, y), w_{n}(c(x, y))\right\}\right\} \mid \\
& \leq \lambda \sup _{y \in D}\left\{|u(x, y)| \max \left\{|p(x, y)|,\left|w_{n}(a(x, y))\right|\right\}\right\} \\
& +(1-\lambda) \sup _{y \in D}\left\{| v ( x , y ) | \operatorname { m a x } \left\{|q(x, y)|,\left|w_{n}(b(x, y))\right|\right.\right. \\
& \left.+|t(x, y)| \max \left\{|r(x, y)|,\left|w_{n}(c(x, y))\right|\right\}\right\} \\
& \leq \lambda \sup _{y \in D}\left\{\max \left\{\psi(\|x\|), \sum_{j=0}^{n} \psi\left(\varphi^{j}(\|a(x, y)\|)\right)\right\}\right\}
\end{aligned}
$$




$$
\begin{aligned}
& +(1-\lambda) \sup _{y \in D}\left\{|v(x, y)| \max \left\{\psi(\|x\|), \sum_{j=0}^{n} \psi\left(\varphi^{j}(\|b(x, y)\|)\right)\right\}\right. \\
& \left.+|t(x, y)| \max \left\{\psi(\|x\|), \sum_{j=0}^{n} \psi\left(\varphi^{j}(\|c(x, y)\|)\right)\right\}\right\} \\
& \leq \lambda \max \left\{\psi(\|x\|), \sum_{j=0}^{n} \psi\left(\varphi^{j+1}(\|x\|)\right)\right\} \\
& \left.+(1-\lambda) \sup _{y \in D}\{|v(x, y)|+|t(x, y)|\} \max \left\{\psi(\|x\|), \sum_{j=0}^{n} \psi\left(\varphi^{j+1}(\|x\|)\right)\right\}\right\} \\
& \leq \lambda\left(\psi(\|x\|)+\sum_{j=0}^{n} \psi\left(\varphi^{j+1}(\|x\|)\right)\right)+(1-\lambda)\left(\psi(\|x\|)+\sum_{j=0}^{n} \psi\left(\varphi^{j+1}(\|x\|)\right)\right) \\
& =\sum_{j=0}^{n+1} \psi\left(\varphi^{j}(\|x\|)\right), \quad \forall(x, k) \in \bar{B}(0, k) \times \mathbb{N},
\end{aligned}
$$

that is, (3.23) is true for $n+1$. Hence (3.23) holds for each $n \in \mathbb{N}_{0}$.

Let $\varepsilon>0$ and $k, n, m \in \mathbb{N}$. Assume that $\operatorname{opt}_{y \in D}=\sup _{y \in D}$. It follows from (3.21) that for each $x_{0} \in \bar{B}(0, k)$ there exist $y, y_{0}, z, z_{0} \in D$ satisfying

$$
\begin{aligned}
& A w_{n+m-1}\left(x_{0}\right)-2^{-1} \varepsilon<u\left(x_{0}, y\right) \operatorname{opt}\left\{p\left(x_{0}, y\right), w_{n+m-1}\left(a\left(x_{0}, y\right)\right)\right\} \\
& A w_{n-1}\left(x_{0}\right)-2^{-1} \varepsilon<u\left(x_{0}, y_{0}\right) \operatorname{opt}\left\{p\left(x_{0}, y_{0}\right), w_{n-1}\left(a\left(x_{0}, y_{0}\right)\right)\right\} \\
& A w_{n+m-1}\left(x_{0}\right) \geq u\left(x_{0}, y_{0}\right) \operatorname{opt}\left\{p\left(x_{0}, y_{0}\right), w_{n+m-1}\left(a\left(x_{0}, y_{0}\right)\right)\right\} \\
& A w_{n-1}\left(x_{0}\right) \geq u\left(x_{0}, y\right) \operatorname{opt}\left\{p\left(x_{0}, y\right), w_{n-1}\left(a\left(x_{0}, y\right)\right)\right\}
\end{aligned}
$$

and

$$
\begin{aligned}
& B w_{n+m-1}\left(x_{0}\right)-2^{-1} \varepsilon< v\left(x_{0}, z\right) \operatorname{opt}\left\{q\left(x_{0}, z\right), w_{n+m-1}\left(b\left(x_{0}, z\right)\right)\right\} \\
&+t\left(x_{0}, z\right) \operatorname{opt}\left\{r\left(x_{0}, z\right), w_{n+m-1}\left(c\left(x_{0}, z\right)\right)\right\} \\
& B w_{n-1}\left(x_{0}\right)-2^{-1} \varepsilon< v\left(x_{0}, z_{0}\right) \operatorname{opt}\left\{q\left(x_{0}, z_{0}\right), w_{n-1}\left(b\left(x_{0}, z_{0}\right)\right)\right\} \\
&+ t\left(x_{0}, z_{0}\right) \operatorname{opt}\left\{r\left(x_{0}, z_{0}\right), w_{n-1}\left(c\left(x_{0}, z_{0}\right)\right)\right\}, \\
& B w_{n+m-1}\left(x_{0}\right) \geq v\left(x_{0}, z_{0}\right) \operatorname{opt}\left\{q\left(x_{0}, z_{0}\right), w_{n+m-1}\left(b\left(x_{0}, z_{0}\right)\right)\right\}+t\left(x_{0}, z_{0}\right) \operatorname{opt}\left\{r\left(x_{0}, z_{0}\right), w_{n+m-1}\left(c\left(x_{0}, z_{0}\right)\right)\right\} \\
& B w_{n-1}\left(x_{0}\right) \geq v\left(x_{0}, z\right) \operatorname{opt}\left\{q\left(x_{0}, z\right), w_{n-1}\left(b\left(x_{0}, z\right)\right)\right\} \\
&+ t\left(x_{0}, z\right) \operatorname{opt}\left\{r\left(x_{0}, z\right), w_{n-1}\left(c\left(x_{0}, z\right)\right)\right\} .
\end{aligned}
$$

On account of (3.24), (3.25) and Lemma 2.2, we obtain that

$$
\begin{aligned}
& A w_{n+m-1}\left(x_{0}\right)-A w_{n-1}\left(x_{0}\right) \\
& \quad<u\left(x_{0}, y\right) \operatorname{opt}\left\{p\left(x_{0}, y\right), w_{n+m-1}\left(a\left(x_{0}, y\right)\right)\right\}-u\left(x_{0}, y\right) \operatorname{opt}\left\{p\left(x_{0}, y\right), w_{n-1}\left(a\left(x_{0}, y\right)\right)\right\}+2^{-1} \varepsilon \\
& \quad \leq\left|u\left(x_{0}, y\right)\right|\left|w_{n+m-1}\left(a\left(x_{0}, y\right)\right)-w_{n-1}\left(a\left(x_{0}, y\right)\right)\right|+2^{-1} \varepsilon
\end{aligned}
$$




$$
\begin{aligned}
A w_{n+m-1}\left(x_{0}\right)-A w_{n-1}\left(x_{0}\right) & \\
> & u\left(x_{0}, y_{0}\right) \operatorname{opt}\left\{p\left(x_{0}, y_{0}\right), w_{n+m-1}\left(a\left(x_{0}, y_{0}\right)\right)\right\} \\
& -u\left(x_{0}, y_{0}\right) \operatorname{opt}\left\{p\left(x_{0}, y_{0}\right), w_{n-1}\left(a\left(x_{0}, y_{0}\right)\right)\right\}-2^{-1} \varepsilon \\
\geq & -\left|u\left(x_{0}, y_{0}\right)\right|\left|w_{n+p-1}\left(a\left(x_{0}, y_{0}\right)\right)-w_{n-1}\left(a\left(x_{0}, y_{0}\right)\right)\right|-2^{-1} \varepsilon ; \\
B w_{n+m-1}\left(x_{0}\right)-B w_{n-1}\left(x_{0}\right) & \\
< & v\left(x_{0}, z\right) \operatorname{opt}\left\{q\left(x_{0}, z\right), w_{n+m-1}\left(b\left(x_{0}, z\right)\right)\right\}+t\left(x_{0}, z\right) \operatorname{opt}\left\{r\left(x_{0}, z\right), w_{n+m-1}\left(c\left(x_{0}, z\right)\right)\right\} \\
\quad & -v\left(x_{0}, z\right) \operatorname{opt}\left\{q\left(x_{0}, z\right), w_{n-1}\left(b\left(x_{0}, z\right)\right)\right\}-t\left(x_{0}, z\right) \operatorname{opt}\left\{r\left(x_{0}, z\right), w_{n-1}\left(c\left(x_{0}, z\right)\right)\right\}+2^{-1} \varepsilon \\
\leq & \left|v\left(x_{0}, z\right)\right|\left|w_{n+p-1}\left(b\left(x_{0}, z\right)\right)-w_{n-1}\left(b\left(x_{0}, z\right)\right)\right| \\
\quad & +\left|t\left(x_{0}, z\right)\right|\left|w_{n+m-1}\left(c\left(x_{0}, z\right)\right)-w_{n-1}\left(c\left(x_{0}, z\right)\right)\right|+2^{-1} \varepsilon
\end{aligned}
$$

and

$$
\begin{aligned}
& B w_{n+m-1}\left(x_{0}\right)-B w_{n-1}\left(x_{0}\right) \\
&> v\left(x_{0}, z_{0}\right) \operatorname{opt}\left\{q\left(x_{0}, z_{0}\right), w_{n+m-1}\left(b\left(x_{0}, z_{0}\right)\right)\right\} \\
&+t\left(x_{0}, z_{0}\right) \operatorname{opt}\left\{r\left(x_{0}, z_{0}\right), w_{n+m-1}\left(c\left(x_{0}, z_{0}\right)\right)\right\} \\
&-v\left(x_{0}, z_{0}\right) \operatorname{opt}\left\{q\left(x_{0}, z_{0}\right), w_{n-1}\left(b\left(x_{0}, z_{0}\right)\right)\right\} \\
& \quad t\left(x_{0}, z_{0}\right) \operatorname{opt}\left\{r\left(x_{0}, z_{0}\right), w_{n-1}\left(c\left(x_{0}, z_{0}\right)\right)\right\}-2^{-1} \varepsilon \\
& \geq-\left|v\left(x_{0}, z_{0}\right)\right|\left|w_{n+m-1}\left(b\left(x_{0}, z_{0}\right)\right)-w_{n-1}\left(b\left(x_{0}, z_{0}\right)\right)\right| \\
&-\left|t\left(x_{0}, z_{0}\right)\right|\left|w_{n+m-1}\left(c\left(x_{0}, z_{0}\right)\right)-w_{n-1}\left(c\left(x_{0}, z_{0}\right)\right)\right|-2^{-1} \varepsilon,
\end{aligned}
$$

which together with (C10), (3.13), (3.20), (3.21) imply that

$$
\begin{aligned}
&\left|w_{n+m}\left(x_{0}\right)-w_{n}\left(x_{0}\right)\right| \\
&=\left|\lambda A w_{n+m-1}\left(x_{0}\right)+(1-\lambda) B w_{n+m-1}\left(x_{0}\right)-\lambda A w_{n-1}\left(x_{0}\right)-(1-\lambda) B w_{n-1}\left(x_{0}\right)\right| \\
& \leq \lambda\left|A w_{n+m-1}\left(x_{0}\right)-A w_{n-1}\left(x_{0}\right)\right|+(1-\lambda)\left|B w_{n+m-1}\left(x_{0}\right)-B w_{n-1}\left(x_{0}\right)\right| \\
& \leq \max \left\{\left|A w_{n+m-1}\left(x_{0}\right)-A w_{n-1}\left(x_{0}\right)\right|,\left|B w_{n+m-1}\left(x_{0}\right)-B w_{n-1}\left(x_{0}\right)\right|\right\} \\
& \leq \max \left\{\left|u\left(x_{0}, y\right)\right|\left|w_{n+m-1}\left(a\left(x_{0}, y\right)\right)-w_{n-1}\left(a\left(x_{0}, y\right)\right)\right|\right. \\
&\left|u\left(x_{0}, y_{0}\right)\right|\left|w_{n+m-1}\left(a\left(x_{0}, y_{0}\right)\right)-w_{n-1}\left(a\left(x_{0}, y_{0}\right)\right)\right| \\
&\left|v\left(x_{0}, z\right)\right|\left|w_{n+m-1}\left(b\left(x_{0}, z\right)\right)-w_{n-1}\left(b\left(x_{0}, z\right)\right)\right| \\
&+\left|t\left(x_{0}, z\right)\right|\left|w_{n+m-1}\left(c\left(x_{0}, z\right)\right)-w_{n-1}\left(c\left(x_{0}, z\right)\right)\right|, \\
&\left|v\left(x_{0}, z_{0}\right)\right|\left|w_{n+m-1}\left(b\left(x_{0}, z_{0}\right)\right)-w_{n-1}\left(b\left(x_{0}, z_{0}\right)\right)\right| \\
&\left.+\left|t\left(x_{0}, z_{0}\right)\right|\left|w_{n+m-1}\left(c\left(x_{0}, z_{0}\right)\right)-w_{n-1}\left(c\left(x_{0}, z_{0}\right)\right)\right|\right\}+2^{-1} \varepsilon \\
& \leq \max \left\{\left|u\left(x_{0}, y\right)\right|,\left|u\left(x_{0}, y_{0}\right)\right|,\left|v\left(x_{0}, z\right)\right|+\left|t\left(x_{0}, z\right)\right|,\left|v\left(x_{0}, z_{0}\right)\right|+\left|t\left(x_{0}, z_{0}\right)\right|\right\} \\
& \times \max \left\{\left|w_{n+m-1}\left(a\left(x_{0}, y\right)\right)-w_{n-1}\left(a\left(x_{0}, y\right)\right)\right|,\left|w_{n+m-1}\left(a\left(x_{0}, y_{0}\right)\right)-w_{n-1}\left(a\left(x_{0}, y_{0}\right)\right)\right|,\right. \\
&\left|w_{n+m-1}\left(b\left(x_{0}, z\right)\right)-w_{n-1}\left(b\left(x_{0}, z\right)\right)\right|,\left|w_{n+m-1}\left(c\left(x_{0}, z\right)\right)-w_{n-1}\left(c\left(x_{0}, z\right)\right)\right|,
\end{aligned}
$$




$$
\begin{aligned}
& \left.\left|w_{n+m-1}\left(b\left(x_{0}, z_{0}\right)\right)-w_{n-1}\left(b\left(x_{0}, z_{0}\right)\right)\right|,\left|w_{n+m-1}\left(c\left(x_{0}, z_{0}\right)\right)-w_{n-1}\left(c\left(x_{0}, z_{0}\right)\right)\right|\right\}+2^{-1} \varepsilon \\
\leq & \max \left\{\left|w_{n+m-1}\left(a\left(x_{0}, y\right)\right)-w_{n-1}\left(a\left(x_{0}, y\right)\right)\right|,\left|w_{n+m-1}\left(a\left(x_{0}, y_{0}\right)\right)-w_{n-1}\left(a\left(x_{0}, y_{0}\right)\right)\right|,\right. \\
& \left|w_{n+m-1}\left(b\left(x_{0}, z\right)\right)-w_{n-1}\left(b\left(x_{0}, z\right)\right)\right|,\left|w_{n+m-1}\left(c\left(x_{0}, z\right)\right)-w_{n-1}\left(c\left(x_{0}, z\right)\right)\right|, \\
& \left.\left|w_{n+m-1}\left(b\left(x_{0}, z_{0}\right)\right)-w_{n-1}\left(b\left(x_{0}, z_{0}\right)\right)\right|,\left|w_{n+m-1}\left(c\left(x_{0}, z_{0}\right)\right)-w_{n-1}\left(c\left(x_{0}, z_{0}\right)\right)\right|\right\}+2^{-1} \varepsilon \\
= & \left|w_{n+m-1}\left(x_{1}\right)-w_{n-1}\left(x_{1}\right)\right|+2^{-1} \varepsilon
\end{aligned}
$$

for some $x_{1} \in\left\{a\left(x_{0}, y_{1}\right), b\left(x_{0}, y_{1}\right), c\left(x_{0}, y_{1}\right)\right\}$ and $y_{1} \in\left\{y, y_{0}, z, z_{0}\right\}$, that is,

$$
\left|w_{n+m}\left(x_{0}\right)-w_{n}\left(x_{0}\right)\right|<\left|w_{n+m-1}\left(x_{1}\right)-w_{n-1}\left(x_{1}\right)\right|+2^{-1} \varepsilon
$$

Similarly, we infer that (3.26) holds for opt ${ }_{y \in D}=\inf _{y \in D}$. Proceeding in this way, we conclude that for each $n \in \mathbb{N}$, there exist $y_{i} \in D$ and $x_{i} \in\left\{a\left(x_{i-1}, y_{i}\right), b\left(x_{i-1}, y_{i}\right), c\left(x_{i-1}, y_{i}\right)\right\}$ for $i \in\{1,2, \ldots, n\}$ such that

$$
\begin{aligned}
& \left|w_{n+m-1}\left(x_{1}\right)-w_{n-1}\left(x_{1}\right)\right| \leq\left|w_{n+m-2}\left(x_{2}\right)-w_{n-2}\left(x_{2}\right)\right|+2^{-2} \varepsilon \\
& \left|w_{n+m-2}\left(x_{2}\right)-w_{n-2}\left(x_{2}\right)\right| \leq\left|w_{n+m-3}\left(x_{3}\right)-w_{n-3}\left(x_{3}\right)\right|+2^{-3} \varepsilon \\
& \ldots \\
& \left|w_{m+1}\left(x_{n-1}\right)-w_{1}\left(x_{n-1}\right)\right| \leq\left|w_{m}\left(x_{n}\right)-w_{0}\left(x_{n}\right)\right|+2^{-n} \varepsilon
\end{aligned}
$$

In terms of $(\varphi, \psi) \in \Phi_{2}$, (C11), (3.23) and (3.27), we deduce that

$$
\begin{aligned}
\left|w_{n+m}\left(x_{0}\right)-w_{n}\left(x_{0}\right)\right| & <\left|w_{m}\left(x_{n}\right)-w_{0}\left(x_{n}\right)\right|+\varepsilon \leq \sum_{j=0}^{m} \psi\left(\varphi^{j}\left(\left\|x_{n}\right\|\right)\right)+\psi\left(\left\|x_{n}\right\|\right)+\varepsilon \\
& \leq \sum_{j=0}^{m} \psi\left(\varphi^{j+n}(k)\right)+\psi\left(\varphi^{n}(k)\right)+\varepsilon \leq \sum_{j=n-1}^{m+n} \psi\left(\varphi^{j}(k)\right)+\varepsilon,
\end{aligned}
$$

which means that

$$
d_{k}\left(w_{n+m}, w_{n}\right) \leq \sum_{j=n-1}^{n+m} \psi\left(\varphi^{j}(k)\right)+\varepsilon
$$

Letting $\varepsilon \rightarrow 0^{+}$in the above inequality, we deduce that

$$
d_{k}\left(w_{n+m}, w_{n}\right) \leq \sum_{j=n-1}^{n+m} \psi\left(\varphi^{j}(k)\right)
$$

Notice that $\sum_{n=0}^{\infty} \psi\left(\varphi^{n}(t)\right)<+\infty$ for each $t>0$. Thus (3.29) means that $\left\{w_{n}\right\}_{n \in \mathbb{N}_{0}}$ is a Cauchy sequence in $(B B(S), d)$ and it converges to some $w \in B B(S)$. Letting $m \rightarrow \infty$ in (3.29), we conclude immediately that

$$
d_{k}\left(w_{n}, w\right) \leq \sum_{j=n-1}^{\infty} \psi\left(\varphi^{j}(k)\right), \quad \forall(k, n) \in \mathbb{N} \times \mathbb{N}
$$


By virtue of (3.22), we infer that

$$
d(H w, w) \leq d\left(H w, H w_{n}\right)+d\left(w_{n+1}, w\right) \leq d\left(w, w_{n}\right)+d\left(w_{n+1}, w\right) \rightarrow 0 \quad \text { as } n \rightarrow \infty,
$$

which yields that $H w=w$, that is, functional equation (1.7) possesses a solution $w \in B B(S)$.

Next we show $(\mathrm{C} 13)$. Let $(x, k) \in \bar{B}(0, k) \times \mathbb{N}$. According to (C11), (3.23) and $(\varphi, \psi) \in \Phi_{2}$, we know that

$$
\begin{aligned}
|w(x)| & \leq\left|w(x)-w_{n}(x)\right|+\left|w_{n}(x)\right| \leq d_{k}\left(w, w_{n}\right)+\sum_{j=0}^{n} \psi\left(\varphi^{j}(\|x\|)\right) \\
& \rightarrow \sum_{j=0}^{\infty} \psi\left(\varphi^{j}(\|x\|)\right) \quad \text { as } n \rightarrow \infty,
\end{aligned}
$$

that is, (C13) holds.

Next we show (C14). Given $\left(x_{0}, k\right) \in \bar{B}(0, k) \times \mathbb{N},\left\{y_{n}\right\}_{n \in \mathbb{N}} \subset D$ and $x_{n} \in\left\{a\left(x_{n-1}, y_{n}\right)\right.$, $\left.b\left(x_{n-1}, y_{n}\right), c\left(x_{n-1}, y_{n}\right)\right\}, \forall n \in \mathbb{N}$. It follows from $(\mathrm{C} 11)$ and $(\varphi, \psi) \in \Phi_{2}$ that

$$
\begin{aligned}
\left\|x_{n}\right\| & \leq \max \left\{\left\|a\left(x_{n-1}, y_{n}\right)\right\|,\left\|b\left(x_{n-1}, y_{n}\right)\right\|,\left\|c\left(x_{n-1}, y_{n}\right)\right\|\right\} \\
& \leq \varphi\left(\left\|x_{n-1}\right\|\right) \leq \cdots \leq \varphi^{n}\left(\left\|x_{0}\right\|\right) \leq \varphi^{n}(k)<k, \quad \forall n \in \mathbb{N}
\end{aligned}
$$

which together with (C11), (3.23) and $(\varphi, \psi) \in \Phi_{2}$ implies that

$$
\begin{aligned}
\left|w\left(x_{n}\right)\right| & \leq\left|w\left(x_{n}\right)-w_{n}\left(x_{n}\right)\right|+\left|w_{n}\left(x_{n}\right)\right| \leq d_{k}\left(w, w_{n}\right)+\sum_{j=0}^{n} \psi\left(\varphi^{j}\left(\left\|x_{n}\right\|\right)\right) \\
& \leq d_{k}\left(w, w_{n}\right)+\sum_{j=n}^{2 n} \psi\left(\varphi^{j}(k)\right) \rightarrow 0 \quad \text { as } n \rightarrow \infty
\end{aligned}
$$

which yields that $\lim _{n \rightarrow \infty} w\left(x_{n}\right)=0$.

Finally we show (C15). Suppose that functional equation (1.7) has another solution $h \in B B(S)$ that satisfies (C14). Let $\varepsilon>0$ and $x_{0} \in S$. It follows from (3.21) that there exist $y, y_{0}, z, z_{0} \in D$ with

$$
\begin{aligned}
& A w\left(x_{0}\right)-2^{-1} \varepsilon<u\left(x_{0}, y\right) \operatorname{opt}\left\{p\left(x_{0}, y\right), w\left(a\left(x_{0}, y\right)\right)\right\} \\
& A h\left(x_{0}\right)-2^{-1} \varepsilon<u\left(x_{0}, y_{0}\right) \operatorname{opt}\left\{p\left(x_{0}, y_{0}\right), h\left(a\left(x_{0}, y_{0}\right)\right)\right\} \\
& A w\left(x_{0}\right)>u\left(x_{0}, y_{0}\right) \operatorname{opt}\left\{p\left(x_{0}, y_{0}\right), w\left(a\left(x_{0}, y_{0}\right)\right)\right\}-2^{-1} \varepsilon, \\
& A h\left(x_{0}\right)>u\left(x_{0}, y\right) \operatorname{opt}\left\{p\left(x_{0}, y\right), h\left(a\left(x_{0}, y\right)\right)\right\}-2^{-1} \varepsilon
\end{aligned}
$$

and

$$
\begin{aligned}
B w\left(x_{0}\right)-2^{-1} \varepsilon< & v\left(x_{0}, z\right) \operatorname{opt}\left\{q\left(x_{0}, z\right), w\left(b\left(x_{0}, z\right)\right)\right\} \\
& +t\left(x_{0}, z\right) \operatorname{opt}\left\{r\left(x_{0}, z\right), w\left(c\left(x_{0}, z\right)\right)\right\}, \\
B h\left(x_{0}\right)-2^{-1} \varepsilon< & v\left(x_{0}, z_{0}\right) \operatorname{opt}\left\{q\left(x_{0}, z_{0}\right), h\left(b\left(x_{0}, z_{0}\right)\right)\right\}
\end{aligned}
$$




$$
\begin{aligned}
+ & t\left(x_{0}, z_{0}\right) \operatorname{opt}\left\{r\left(x_{0}, z_{0}\right), h\left(c\left(x_{0}, z_{0}\right)\right)\right\}, \\
B w\left(x_{0}\right)> & v\left(x_{0}, z_{0}\right) \operatorname{opt}\left\{q\left(x_{0}, z_{0}\right), w\left(b\left(x_{0}, z_{0}\right)\right)\right\} \\
& +t\left(x_{0}, z_{0}\right) \operatorname{opt}\left\{r\left(x_{0}, z_{0}\right), w\left(c\left(x_{0}, z_{0}\right)\right)\right\}-2^{-1} \varepsilon, \\
B h\left(x_{0}\right)> & v\left(x_{0}, z\right) \operatorname{opt}\left\{q\left(x_{0}, z\right), h\left(b\left(x_{0}, z\right)\right)\right\} \\
& +t\left(x_{0}, z\right) \operatorname{opt}\left\{r\left(x_{0}, z\right), h\left(c\left(x_{0}, z\right)\right)\right\}-2^{-1} \varepsilon,
\end{aligned}
$$

which together with (C11), (3.20) and (3.21) yield that there exist $x_{1} \in\left\{a\left(x_{0}, y_{1}\right), b\left(x_{0}, y_{1}\right)\right.$, $\left.c\left(x_{0}, y_{1}\right)\right\}$ and $y_{1} \in\left\{y, y_{0}, z, z_{0}\right\}$ satisfying

$$
\begin{aligned}
&\left|w\left(x_{0}\right)-h\left(x_{0}\right)\right| \\
&=\left|\lambda A w\left(x_{0}\right)+(1-\lambda) B w\left(x_{0}\right)-\lambda A h\left(x_{0}\right)-(1-\lambda) B h\left(x_{0}\right)\right| \\
& \leq \lambda\left|A w\left(x_{0}\right)-A h\left(x_{0}\right)\right|+(1-\lambda)\left|B w\left(x_{0}\right)-B h\left(x_{0}\right)\right| \\
& \leq \max \left\{\left|A w\left(x_{0}\right)-A h\left(x_{0}\right)\right|,\left|B w\left(x_{0}\right)-B h\left(x_{0}\right)\right|\right\} \\
&< \max \left\{\left|u\left(x_{0}, y\right)\right|\left|\operatorname{opt}\left\{p\left(x_{0}, y\right), w\left(a\left(x_{0}, y\right)\right)\right\}-\operatorname{opt}\left\{p\left(x_{0}, y\right), h\left(a\left(x_{0}, y\right)\right)\right\}\right|\right. \\
&\left|u\left(x_{0}, y_{0}\right)\right|\left|\operatorname{opt}\left\{p\left(x_{0}, y_{0}\right), w\left(a\left(x_{0}, y_{0}\right)\right)\right\}-\operatorname{opt}\left\{p\left(x_{0}, y_{0}\right), h\left(a\left(x_{0}, y_{0}\right)\right)\right\}\right| \\
& \mid v\left(x_{0}, z\right) \operatorname{opt}\left\{q\left(x_{0}, z\right), w\left(b\left(x_{0}, z\right)\right)\right\}+t\left(x_{0}, z\right) \operatorname{opt}\left\{r\left(x_{0}, z\right), w\left(c\left(x_{0}, z\right)\right)\right\} \\
&-v\left(x_{0}, z\right) \operatorname{opt}\left\{q\left(x_{0}, z\right), h\left(b\left(x_{0}, z\right)\right)\right\}-t\left(x_{0}, z\right) \operatorname{opt}\left\{r\left(x_{0}, z\right), h\left(c\left(x_{0}, z\right)\right)\right\} \mid, \\
& \mid v\left(x_{0}, z_{0}\right) \operatorname{opt}\left\{q\left(x_{0}, z_{0}\right), w\left(b\left(x_{0}, z_{0}\right)\right)\right\}+t\left(x_{0}, z_{0}\right) \operatorname{opt}\left\{r\left(x_{0}, z_{0}\right), w\left(c\left(x_{0}, z_{0}\right)\right)\right\} \\
&\left.-v\left(x_{0}, z_{0}\right) \operatorname{opt}\left\{q\left(x_{0}, z_{0}\right), h\left(b\left(x_{0}, z_{0}\right)\right)\right\}-t\left(x_{0}, z_{0}\right) \operatorname{opt}\left\{r\left(x_{0}, z_{0}\right), h\left(c\left(x_{0}, z_{0}\right)\right)\right\} \mid\right\}+\varepsilon \\
& \leq \max \left\{\left|u\left(x_{0}, y\right)\right|,\left|u\left(x_{0}, y_{0}\right)\right|,\left|v\left(x_{0}, z\right)\right|+\left|t\left(x_{0}, z\right)\right|,\left|v\left(x_{0}, z_{0}\right)\right|+\left|t\left(x_{0}, z_{0}\right)\right|\right\} \\
& \times \max \left\{\left|w\left(a\left(x_{0}, y\right)\right)-h\left(a\left(x_{0}, y\right)\right)\right|,\left|w\left(a\left(x_{0}, y_{0}\right)\right)-h\left(a\left(x_{0}, y_{0}\right)\right)\right|\right. \\
&\left|w\left(b\left(x_{0}, z\right)\right)-h\left(b\left(x_{0}, z\right)\right)\right|,\left|w\left(c\left(x_{0}, z\right)\right)-h\left(c\left(x_{0}, z\right)\right)\right|, \\
&\left.\left|w\left(b\left(x_{0}, z_{0}\right)\right)-h\left(b\left(x_{0}, z_{0}\right)\right)\right|,\left|w\left(c\left(x_{0}, z_{0}\right)\right)-h\left(c\left(x_{0}, z_{0}\right)\right)\right|\right\}+\varepsilon \\
& \leq\left|w\left(x_{1}\right)-h\left(x_{1}\right)\right|+\varepsilon,
\end{aligned}
$$

that is,

$$
\left|w\left(x_{0}\right)-h\left(x_{0}\right)\right|<\left|w\left(x_{1}\right)-h\left(x_{1}\right)\right|+\varepsilon .
$$

Similarly, we infer that for each $n \in \mathbb{N} \backslash\{1\}$, there exist $x_{i} \in\left\{a\left(x_{i-1}, y_{i}\right), b\left(x_{i-1}, y_{i}\right), c\left(x_{i-1}, y_{i}\right)\right\}$ and $y_{i} \in D, i \in\{2,3, \ldots, n\}$, such that

$$
\begin{aligned}
& \left|w\left(x_{1}\right)-h\left(x_{1}\right)\right|<\left|w\left(x_{2}\right)-h\left(x_{2}\right)\right|+2^{-1} \varepsilon, \\
& \left|w\left(x_{2}\right)-h\left(x_{2}\right)\right|<\left|w\left(x_{3}\right)-h\left(x_{3}\right)\right|+2^{-2} \varepsilon, \\
& \ldots \\
& \left|w\left(x_{n-1}\right)-h\left(x_{n-1}\right)\right|<\left|w\left(x_{n}\right)-h\left(x_{n}\right)\right|+2^{-n+1} \varepsilon .
\end{aligned}
$$


Using (3.30) and (3.31), we deduce that

$$
\left|w\left(x_{0}\right)-h\left(x_{0}\right)\right|<\left|w\left(x_{n}\right)-h\left(x_{n}\right)\right|+2 \varepsilon \rightarrow 2 \varepsilon \quad \text { as } n \rightarrow \infty .
$$

Letting $\varepsilon \rightarrow 0^{+}$in the above inequality, we infer that $w\left(x_{0}\right)=h\left(x_{0}\right)$. This completes the proof.

Remark 3.9 Theorem 3.8 generalizes Theorem 3.5 in $[5,6,12]$, Corollaries 2.2 and 2.3 in [11], Corollaries 3.1, 3.3 and 3.4 in [14], Theorems 2.3 and 2.4 in [15], Theorem 2.6 in [16] and Theorem 3.4 in [19]. The example below shows that Theorem 3.8 extends properly the corresponding results in $[5,6,11,12,14-16,19]$.

Example 3.10 Consider the functional equation

$$
\begin{aligned}
f(x)= & \lambda \underset{y \in \mathbb{R}^{-}}{\operatorname{opt}}\left\{\frac{\sin ^{49}\left(x^{35} y^{27}\right)}{\left(x-y^{2}\right)^{4}+1} \text { opt }\left\{\frac{x^{8} y^{6}}{x^{2} y^{6}+1}, f\left(\frac{x^{8} y^{2}}{\left(2 x^{7}+1\right)\left(y^{2}+1\right)}\right)\right\}\right\} \\
+ & (1-\lambda) \text { opt }\left\{\frac{\left(x^{3}+1\right) \cos ^{2}(x y)}{x^{3}-y \mathbb{R}^{5}+1} \text { opt }\left\{\frac{x^{21} y^{5}}{x^{13} y^{5}-1}, f\left(\frac{x^{7} y^{4}}{\sqrt{4 x^{12} y^{8}+1}}\right)\right\}\right. \\
& +\frac{\left(x^{3}+1\right) \sin ^{2}(x y)}{x^{3}-y x^{5}+1} \text { opt }\left\{\frac{x^{32} y^{4}}{x^{26} y^{4}+\cos ^{2}\left(x^{3} y\right)}, f\left(x \sin ^{2}\left(\frac{1}{\sqrt{2}+x y^{2}}\right)\right)\right\}, \\
& \forall x \in \mathbb{R}^{+} .
\end{aligned}
$$

Let $\lambda \in[0,1], X=Y=\mathbb{R}, S=\mathbb{R}^{+}, D=\mathbb{R}^{-}$. Let $p, q, r, u, v, t: S \times D \rightarrow \mathbb{R}, a, b, c: S \times D \rightarrow S$, $\varphi$ and $\psi: \mathbb{R}^{+} \rightarrow \mathbb{R}^{+}$be defined by

$$
\begin{aligned}
& p(x, y)=\frac{x^{8} y^{6}}{x^{2} y^{6}+1}, \quad q(x, y)=\frac{x^{21} y^{5}}{x^{13} y^{5}-1}, \quad r(x, y)=\frac{x^{32} y^{4}}{x^{26} y^{4}+\cos ^{2}\left(x^{3} y\right)}, \\
& u(x, y)=\frac{\sin ^{49}\left(x^{35} y^{27}\right)}{\left(x-y^{2}\right)^{4}+1}, \quad v(x, y)=\frac{\left(x^{3}+1\right) \cos ^{2}(x y)}{x^{3}-y x^{5}+1}, \\
& t(x, y)=\frac{\left(x^{3}+1\right) \sin ^{2}(x y)}{x^{3}-y x^{5}+1}, \quad a(x, y)=\frac{x^{8} y^{2}}{\left(2 x^{7}+1\right)\left(y^{2}+1\right)}, \\
& b(x, y)=\frac{x^{7} y^{4}}{\sqrt{4 x^{12} y^{8}+1}}, \quad c(x, y)=x \sin ^{2}\left(\frac{1}{\sqrt{2}+x y^{2}}\right), \quad \forall(x, y) \in S \times D, \\
& \varphi(t)=\frac{t}{2}, \quad \psi(t)=\max \left\{t^{6}, t^{8}\right\}, \quad \forall t \in \mathbb{R}^{+} .
\end{aligned}
$$

Obviously, the conditions of Theorem 3.8 are satisfied. It follows from Theorem 3.8 that functional equation (3.32) possesses a unique solution $w \in B B(S)$ satisfying (C11)-(C14). However, Theorem 3.5 in [5, 6, 12], Corollaries 2.2 and 2.3 in [11], Corollaries 3.1, 3.3 and 3.4 in [14], Theorems 2.3 and 2.4 in [15], Theorem 2.6 in [16] and Theorem 3.4 in [19] are not applicable to functional equation (3.32). 
Authors' contributions

All authors read and approved the final manuscript.

\section{Author details}

'Department of Mathematics, Liaoning Normal University, Dalian, Liaoning 116029, People's Republic of China. ${ }^{2}$ Dalian No. 76 Middle School, Dalian, Liaoning 116031, People's Republic of China. ${ }^{3}$ Department of Mathematics and RINS, Gyeongsang National University, Jinju, 660-701, Korea.

\section{Acknowledgements}

This research was supported by the Science Research Foundation of Educational Department of Liaoning Province (L2012380).

Received: 11 July 2013 Accepted: 10 September 2013 Published: 08 Nov 2013

\section{References}

1. Bellman, R: Some functional equations in the theory of dynamic programming I. Functions of points and point transformations. Trans. Am. Math. Soc. 80, 51-71 (1955). doi:10.2307/1993005

2. Bellman, R: Dynamic Programming. Princeton University Press, Princeton (1957)

3. Bellman, R, Lee, ES: Functional equations arising in dynamic programming. Aequ. Math. 17, 1-18 (1978). doi:10.1007/BF01818535

4. Bellman, R, Roosta, M: A technique for the reduction of dimensionality in dynamic programming. J. Math. Anal. Appl. 88, 543-546 (1982). doi:10.1016/0022-247X(82)90212-8

5. Bhakta, PC, Choudhury, SR: Some existence theorems for functional equations arising in dynamic programming 11 . J. Math. Anal. Appl. 131, 217-231 (1988). doi:10.1016/0022-247X(88)90201-6

6. Bhakta, PC, Mitra, S: Some existence theorems for functional equations arising in dynamic programming. J. Math. Anal. Appl. 98, 348-362 (1984). doi:10.1016/0022-247X(84)90254-3

7. Liu, Z: Coincidence theorems for expansion mappings with applications to the solutions of functional equations arising in dynamic programming. Acta Sci. Math. 65, 359-369 (1999)

8. Liu, Z: Compatible mappings and fixed points. Acta Sci. Math. 65, 371-383 (1999)

9. Liu, Z: Existence theorems of solutions for certain classes of functional equations arising in dynamic programming. J. Math. Anal. Appl. 262, 529-553 (2001). doi:10.1006/jmaa.2001.7551

10. Liu, Z, Agarwal, RP, Kang, SM: On solvability of functional equations and system of functional equations arising in dynamic programming. J. Math. Anal. Appl. 297, 111-130 (2004). doi:10.1016/j.jmaa.2004.04.049

11. Liu, Z, Kang, SM: Properties of solutions for certain functional equations arising in dynamic programming. J. Glob. Optim. 34, 273-292 (2006). doi:10.1007/s10898-005-2605-6

12. Liu, Z, Kang, SM: Existence and uniqueness of solutions for two classes of functional equations arising in dynamic programming. Acta Math. Appl. Sin. 23, 195-208 (2007). doi:10.1007/s10255-007-0363-6

13. Liu, Z, Kang, SM, Ume, JS: Solvability and convergence of iterative algorithms for certain functional equations arising in dynamic programming. Optimization 59, 887-916 (2010). doi:10.1080/02331930902884182

14. Liu, Z, Ume, JS: On properties of solutions for a class of functional equations arising in dynamic programming J. Optim. Theory Appl. 117, 533-551 (2003)

15. Liu, Z, Ume, JS, Kang, SM: Some existence theorems for functional equations arising in dynamic programming. J. Korean Math. Soc. 43, 11-28 (2006)

16. Liu, Z, Ume, JS, Kang, SM: Some existence theorems for functional equations and system of functional equations arising in dynamic programming. Taiwan. J. Math. 14, 1517-1536 (2010)

17. Liu, Z, Ume, JS, Kang, SM: On properties of solutions for two functional equations arising in dynamic programming Fixed Point Theory Appl. 2010, Article ID 905858 (2010). doi:10.1155/2010/905858

18. Liu, Z, Xu, YG, Ume, JS, Kang, SM: Solutions to two functional equations arising in dynamic programming. J. Comput. Appl. Math. 192, 251-269 (2006). doi:10.1016/j.cam.2005.04.033

19. Liu, Z, Zhao, L, Kang, SM, Ume, JS: On the solvability of a functional equation. Optimization 60, 365-375 (2011). doi:10.1080/02331930903121311

10.1186/1029-242X-2013-516

Cite this article as: Liu et al.: Solving a class of functional equations using fixed point theorems. Journal of Inequalities and Applications 2013, 2013:516 